\title{
Karl Härter, Strafrechts- und Kriminalitätsgeschichte der Frühen Neuzeit
}

Berlin, Boston, De Gruyter/Oldenbourg, coll. « methodica-Einführungen in die rechtshistorische Forschung ", 2018, 204 p., ISBN:

978-3-11-037979-2

Falk Bretschneider

\section{(2) OpenEdition}

Édition électronique

URL : https://journals.openedition.org/chs/2934

DOI : $10.4000 /$ chs. 2934

ISSN : 1663-4837

Éditeur

Librairie Droz

Édition imprimée

Date de publication : 5 août 2021

Pagination : 143-144

ISSN : 1422-0857

Référence électronique

Falk Bretschneider, « Karl Härter, Strafrechts- und Kriminalitätsgeschichte der Frühen Neuzeit », Crime,

Histoire \& Sociétés / Crime, History \& Societies [En ligne], vol. 25, $n^{\circ} 1$ | 2021, mis en ligne le 05 août 2021 consulté le 09 novembre 2022. URL : http://journals.openedition.org/chs/2934 ; DOl : https://doi.org/ $10.4000 /$ chs.2934

Ce document a été généré automatiquement le 9 novembre 2022

Tous droits réservés 


\section{Karl Härter, Strafrechts- und Kriminalitätsgeschichte der Frühen Neuzeit}

Berlin, Boston, De Gruyter/Oldenbourg, coll. « methodica-Einführungen in die rechtshistorische Forschung ", 2018, 204 p., ISBN:

978-3-11-037979-2

Falk Bretschneider

\section{RÉFÉRENCE}

Karl Härter, Strafrechts- und Kriminalitätsgeschichte der Frühen Neuzeit, Berlin, Boston, De Gruyter/Oldenbourg, coll. « methodica-Einführungen in die rechtshistorische Forschung », 2018, 204 p., ISBN: 978-3-11-037979-2

1 Il y a vingt ou trente années, l'histoire de la criminalité et de la justice pénale accusait encore, en Allemagne, un certain retard par rapport à d'autres historiographies, notamment anglaise et française. Ce retard, peut-on dire sans trop s'avancer, est rattrapé. En témoignent notamment les manuels proposant d'introduire le lecteur aux débats scientifiques centraux et les principales sources et techniques de travail du champ. Celui de G. Schwerhoff, paru sous le titre Historische Kriminalitätsforschung pour la première fois en 1999 et réédité en 2011 dans une version retravaillée, adopte une perspective d'histoire sociale, en mettant l'accent sur la recherche internationale, les débats théoriques et méthodologiques et les apports importants d'autres disciplines (sociologie, criminologie ou anthropologie, notamment). Parmi ces dernières, figure également l'histoire du droit dont le dialogue avec les historiens généralistes ne s'est pourtant pas toujours opéré sans malentendus et sentiments d'incompréhension. Il n'est donc pas étonnant que ce soit K. Härter - historien de formation, mais depuis de nombreuses années collaborateur scientifique à l'Institut Max-Planck d'histoire européenne du droit à Francfort/M. (où il a notamment établi et dirigé, avec M. Stolleis, 
l'éminente collection des ordonnances de police du Saint-Empire ainsi que de ses territoires et villes), donc un passeur parfait entre les deux disciplines - qui nous propose désormais un deuxième manuel, orienté davantage vers le droit pénal et son interprétation, sans pour autant oublier les autres sources et méthodes d'une analyse historique du fait pénal.

2 Paru dans la collection «methodica ", publiée par l'Institut francfortois et destinée en premier lieu à un public d'étudiants, mais aussi à des chercheurs d'autres domaines qui souhaitent avoir une vue d'ensemble, l'ouvrage se partage en quatre parties. La première est consacrée à un bref aperçu sur les orientations globales de l'histoire du droit pénal et de la recherche historique sur la criminalité (Historische Kriminalitätsforschung, nom allemand donné au champ de l'histoire sociale de la justice pénale et de la criminalité). S'il ne dissimule pas les insuffisances d'un travail intéressé uniquement par l'évolution des institutions et des normes (comme c'est souvent le cas chez les historiens du droit), l'auteur pointe également des déficits récurrents chez les tenants de l'histoire sociale (une lecture naïve du discours juridique ou une connaissance souvent limitée des procédures pénales, par exemple). Par conséquent, il souligne l'importance de chacune des deux disciplines et la nécessité de leur coopération. La deuxième partie, de loin la plus longue, fournit une présentation des principales sources disponibles dans ce champ: normes pénales (ordonnances criminelles, législation de police, science juridique, etc.), sources de la pratique (livres des juridictions médiévales, dossiers de l'instruction, productions de l'appareil répressif, mais aussi suppliques ou demandes de grâce), médias populaires. Chaque genre est discuté en renvoyant aux problèmes de conservation et de transmission, aux éditions éventuelles et, surtout, aux différentes méthodes d'exploitation et d'interprétation. La troisième partie, enfin, brosse à grands traits un tableau des principales controverses (clivage entre normes et pratiques, "civilisation» de la violence, usages de la justice et règlement infrajudiciaire des conflits, modernisation et changement historique, par exemple) qui animent les discussions des historiens du pénal. Une bibliographie représentative complète le livre.

3 Le manuel proposé par K. Härter se distingue par une "perspective intégratrice» (p. VII) donnant aux normes du droit la place qui leur revient sans en faire le seul pivot de l'histoire de la justice pénale. Il se démarque en outre par sa large perspective sur une période moderne longue ( $\mathrm{du} \mathrm{XV}^{\mathrm{e}}$ au début du XIX ${ }^{\mathrm{e}}$ siècle), l'attention portée aux méthodes d'interprétation d'un éventail important de sources et une présentation parallèle des apports de l'histoire du droit pénal et de l'histoire sociale de la criminalité. Tout cela en fait un manuel extrêmement utile pour les étudiants, non seulement en Allemagne, mais aussi un outil de travail précieux pour tout chercheur s'intéressant à ou travaillant dans ce domaine. En se concentrant sur la justice pénale du Saint-Empire germanique, il apporte d'ailleurs un intéressant éclaircissement sur le fonctionnement institutionnel de cet ensemble politique qui paraît toujours aussi étrange à la plupart des historiens. 


\section{AUTEURS}

\section{FALK BRETSCHNEIDER}

EHESS/Centre Georg Simmel

Bretschn[at]ehess.fr 